\title{
Calendar of Events
}

August 15 - 20, 1999. IXth Congress of the International Psychogeriatric Association will be held in Vancouver, British Columbia, Canada. Contact: Conference Secretariat, Venue West Conference Services, 645 - 375 Water Street, Vancouver BC Canada V6B 5C6. Tel: (604) 681-5226; Fax: (604) 6812503; E-mail: congress@venuewest.com

September 1 - 4, 1999. The 1999 North American Stroke Meeting will be held in Aspen, Colorado. For more information, contact: The National Stroke Association, '99 NASM, 96 Inverness Drive East, Ste I, Englewood, CO 80112-5112. Tel: (303) 745-0919; Fax (303) 649-1328.

October 3 - 6, 1999. First International Congress on Vascular Dementia will be held in Geneva Switzerland. Contact: Prof Amos D. Korczyn, c/o Kuoni Congress, 7 Rue de Berne, $\mathrm{CH}$ 1201, Geneva, Switzerland. Tel: +41 (22) 908-1855; Fax: +41 (22) 908-18351 E-mail: vascular@kuoni.ch

October 6 - 10, 1999. The American Association for Electrodiagnostic Medicine will be held in Vancouver, BC Canada. Contact: American Association of Electrodiagnostic Medicine, 21 Second Street SW, Suite 103, Rochester MN USA 55902. Tel: (507) 288-0100; Fax: (507) 288-1225.

October 20 - 23, 1999. The 2nd International Congress on Mental Dysfunction in Parkinson's Disease will be held in Amsterdam, The Netherlands. Contact: Congress Office SCEM, ms. M. de Haan, PO Box 21, 4196 ZG Tricht, The Netherlands. Tel: +31 (0)345 576642; Fax: +31 (0)345 571781; E-mail: scem@scem.nl

October 21 - 22, 1999. 2nd Croatian Neurosurgical Congress will be held in Rijeka, Croatia. Contact: Rijeka University Department of Neurosurgery, Dr. Eškinja and Dr. Girotto. Tel: 38 551 217-713; Fax: 38 551 218-861; E-mail rihnk2@yahoo.com

October 22 - 24, 1999. The Scottsdale Headache Symposium will be held in Scottsdale, Arizona, USA. Contact: American Association for the Study of Headache. 19 Mantua Road, Mt. Royal, NJ USA 08096. Tel: (609) 423-0043; Fax: (609) 4230082; E-mail: aashq@aash.smarthub.com; Internet: www.aash.org

November 2, 1999 - April 30, 2000. Brainwork: an exhibition to mark the 75th Anniversary of Neurosurgery in Canada will be held in Toronto. For more information, contact: Felicity Pope, Curator, Canadian Museum of Health and Medicine, The Toronto Hospital. Tel: (416) 340-4800 ext.1899; E-mail fpope@torhosp.toronto.on.ca

January 14 - 16, 2000. Headache Now/Puerto Rico 2000 will be held in San Juan, Puerto Rico. Contact: American Association for the Study of Headache, 19 Mantua Road, Mt. Royal, NJ USA 08096. Tel: (609)423-0043; Fax: (609)423-0082; E-mail: aashq@aash.smarthub.com; Internet:www.aash.org

April 9-13, 2000. 27th Annual meeting of the International Society for the Study of the Lumbar Spine will be held in Adelaide, Australia. Abstracts should be submitted before October 1, 1999. Contact: Dr. Marek Szpalski, Secretary, ISSLS, Sunnybrook Health Science Centre, Room MG 323, 2075 Bayview Avenue, Toronto, Canada M4N 3M5. E-mail: ISSLS@aol.com
April 10-15, 2000. Toward a Science of Consciousness an interdisciplinary meeting for researchers in psychology, philosophy, neuroscience, anthropology and other disciplines will be held in Tucson, AZ, USA. Contact: Jim Laukes, Consciousness Studies, University of Arizona Extended University, PO 210158, Tucson, AZ 85721-0158. Tel: (520) 626-9061; Fax (520)621-3269; Email:jlaukes@u.arizona.edu

June 13 - 17, 1999. The 35th Annual Meeting of the Canadian Congress of Neurological Sciences will be held in the Ottawa Convention Centre, Ottawa, Ontario, Canada. Contact: Venue West Conference Services, 645 - The Landing, 375 Water Street, Vancouver, BC Canada V6B 5C6. Tel: (604) 681-5226; Fax: (604) 681-2503. E-mail: congress@venuewest.com

June 23 - 25, 2000. 42nd Annual Scientific Meeting of the the American Association for the Study of Headache will be held in Montreal, Quebec. Contact: American Association for the Study of Headache, 19 Mantua Road, Mt. Royal, NJ USA 08096. Tel: (609) 423-0043; Fax: (609) 423-0082; E-mail: aashq@aash.smarthub.com; Internet: www.aash.org

August 27 - August 31, 2000. The 1st International Brain Exposition and Congress will be held in Hamburg, Germany. Contact: International Academy on Brain and Nervous System Health, CCH-Congress Organisation, St. Peterburger Straße 1, 20355 Hamburg, Germany. Tel: +49403569 2246; Fax: +49 40 3569 2343; E-mail: brain2000@cch.de

August 27 - September 1, 2000. The First Interdisciplinary World Congress on Spinal Surgery will be held in Berlin, Germany. Contact: Prof. Dr. med Dr. h.c. Mario Brock, Neurochirurgische Klinik, Universitatsklinikum Benjamin Franklin, 12200 Berlin, Germany. Tel: +49 (30) 8445 2798; Fax: +49 (30) 8445 2798; E-mail: neurochirurgie@medizin.fuberlin.de

September 3 - 6, 2000. The XIVth International Congress of Neuropathology will be held in Birmingham, England, UK. Contact: Congress Secretariat, 4B, 50 Speirs Wharf, Port Dundas, Glasgow, G4 9TB. Tel: +44 (0) 141331 0123; Fax: +44 (0) 141331 0234; E-mail: info@neuropathology2000.co.uk

September 9 - 16, 2000. 4th World Stroke Congress will be held in Melbourne, Australia Contact: Conference Action Pty Ltd. PO Box 1231, North Sydney, NSW, Australia. Tel: +61 (29) 956-8333; Fax +61 (29) 956-5154; E-mail: confact@real.net.au

November 3 - 5, 2000. Scottsdale Headache Symposium will be held in Scottsdale, Arizona, USA. Contact: American Association for the Study of Headache. 19 Mantua Road, Mt. Royal, NJ USA 08096. Tel: (609) 423-0043; Fax: (609) 4230082; E-mail: aashq@aash.smarthub.com; Internet: www.aash.org

March 21 - 24, 2001. 5th International Conference on Stroke and 2nd Conference of the Mediterranean Stroke Society will be held in Istanbul, Turkey. Contact: Prof. N.M. Bornstein, Stroke 2001, P.O. Box 50006, Tel Aviv 61500, Israel. Tel: +972 3 514-0018/9; Fax: $+9723517-5674$ or $+9723514-0077$ 